Comments on "On Conjoint Analysis and Quantal Choice Models"

Author(s): Charles R. Plott

Source: The Tournal of Business, Vol. 53, No. 3, Part 2: Interfaces Between Marketing and

Economics (Jul., 1980), pp. S45-S46

Published by: The University of Chicago Press

Stable URL: http://www.jstor.org/stable/2352209

Accessed: 20/02/2014 13:53

Your use of the JSTOR archive indicates your acceptance of the Terms \& Conditions of Use, available at

http://www.jstor.org/page/info/about/policies/terms.jsp

JSTOR is a not-for-profit service that helps scholars, researchers, and students discover, use, and build upon a wide range of content in a trusted digital archive. We use information technology and tools to increase productivity and facilitate new forms of scholarship. For more information about JSTOR, please contact support@jstor.org. 


\section{Comments on "On Conjoint Analysis and Quantal Choice Models"'}

Two points touched upon in the Madansky paper (this issue) could use elaboration, and a third point needs to be introduced. The first point is sufficiently obvious to those who work on the theoretical aspects of measurement theory, but perhaps it is not so obvious to those with applied proclivities.

Sometimes, users of conjoint analysis criticize economics for assuming too much. As it turns out, the use of conjoint analysis presupposes the applicability of all the assumptions typical of economic preference theory and then some. Typically, economists assume no more than the existence of a complete, transitive preference relation over the "bundles" (to use Madansky's terminology). A random variable signifying some unobserved or perhaps unmeasured and impossible to control "influences" can be added to deal with the obvious problems of inconsistent subject choices.

Since conjoint analysis assumes the existence of a utility function (for the additive case) $U\left(i_{1}, \ldots, i_{n}\right)=V\left(1, i_{1}\right)+V\left(n, i_{n}\right)$, the theory automatically presupposes everything found in the typical economic theoretic model. The level surfaces of $U\left(i_{1}, \ldots, i_{n}\right)$ simply trace out the indifference curves which have the additional property now (by virtue of conjoint theory) of being straight lines.

Thus those who apply conjoint analysis and criticize economic theory are not claiming that economic theory assumes too much. The implicit criticism these scholars have of economics is that it assumes too little. The added assumptions and not the lack of assumptions induce testable propositions and predictions. It is in this same spirit of adding structure to the traditional model and not discarding it that the quantal models were developed.

The second point that should be emphasized pertains to the nature of utility. All of these theories are ordinal in the economics sense of the term. Notice that if $f(\cdot)$ is a positive monotone transformation and if 
$U\left(i_{1}, \ldots, i_{n}\right)$ is the utility function resulting from the conjoint analysis, then $f\left[U\left(i_{1}, \ldots, i_{n}\right)\right]$ is also a utility function in the sense that it captures all relevant aspects of the underlying preference. Thus $U(\cdot)$ is ordinal. The individual "component" functions $V\left(j, i_{j}\right)$ when viewed ordinally are interpreted within the "marginal rate of substitution" formula

$$
\frac{V(j, x)-V(j, x-1)}{V\left(j^{\prime}, x^{\prime}\right)-V\left(j^{\prime}, x^{\prime}-1\right)} \text {. }
$$

With this interpretation (except for discreteness) the conjoint model can be seen as a special case of ordinal economic preference theory. Similarly, the quantal choice model can be stated within an ordinal framework. Thus, except for a vehicle to avoid the cumbersome analytics of ordinal theory, cardinal utility (in the economist's sense) is unnecessary.

The final point is with reference to the "preference reversal" phenomenon, which on our interpretation is inconsistent with the basic assumptions of both conjoint analysis and quantal choice. Many individuals will express a preference for one "bundle" in a pair but then exhibit a systematic tendency (see Lichtenstein and Slovic 1971; Grether and Plott 1979) to place a higher monetary value on the other "bundle." This type of "intransitivity" cannot be incorporated in either model. Thus even though conjoint analysis and quantal choice models may be very useful, they are both "wrong" in a basic theoretical sense. The interesting question then becomes not "Which is right?" but instead "Why do they work at all?"

\section{References}

Grether, D. M., and Plott, C. R. 1979. Economic theory of choice and the preference reversal phenomenon. American Economic Review 69 (September): 623-38.

Lichtenstein, Sarah, and Slovic, P. 1971. Reversals of preferences between bids and choices in gambling decisions. Journal of Experimental Psychology 89, no. 1 (July): 46-55. 